\title{
Procesos de «atrincheramiento»: un análisis etnográfico sobre las dinámicas de consolidación en la situación de calle
}

\section{"Entrenchment" processes: an ethnographic analysis of the dynamics and consolidation of the homeless}

\author{
Santiago BACHILLER \\ Universidad Nacional de la Patagonia Austral \\ santiago.bachiller@gmail.com
}

Recibido: 08/04/2014

Revisado: 16/06/2014

Aceptado: 24/07/2014

Disponible on line: 10/12/2014

\begin{abstract}
Resumen
Como resultado de un trabajo de campo etnográfico con personas sin hogar, el objetivo del artículo consiste en analizar los procesos de «atrincheramiento» o consolidación y afianzamiento de la situación de calle. La mayoría de las personas en situación de calle sostienen que la vía pública no es su hogar. No obstante, para subsistir y hacer más llevadera su situación, cotidianamente se ven forzados a apropiarse y personalizar temporalmente ciertos sectores del espacio público. Significativamente, tales prácticas y discursos suelen representar el esfuerzo por asemejar, en lo posible, los espacios apropiados con un hogar. Desde ya que tales intentos son estériles; no obstante, dan cuenta de cómo, a medida que transcurren los años, la frontera que delimita la calle del hogar comienza a difuminarse. Los procesos de atrincheramiento analizados guardan relación con la socialización prolongada en la situación de calle, la cual altera la percepción de los sujetos y minimiza las posibilidades de escapar de sus dominios.
\end{abstract}

Palabras clave: personas sin hogar, hogar, calle, experiencia de habitar, procesos de atrincheramiento.

\begin{abstract}
Resulting from ethnographic field work with homeless people, the main goal of this article is to analyze the «entrenchment» processes that imply the consolidation of homelessness. Most homeless people would declare the streets are not their home. But, in order to survive and make things easier for them, daily they feel forced to appropriate particular public spaces. Such practices and discourses of appropriation usually represent the effort to make these public spaces to look like a home. These efforts are in vain and they show how, as the years pass, the limit that separates the street from home starts to fade out. These «entrenchment» processes are related to long term homelessness and the way in which it alters the subject's perception and minimizes the chances of escaping from it.
\end{abstract}

Keywords: homeless, home, street, entrenchment process.

Referencia normalizada: Bachiller, S. (2014): «Procesos de "atrincheramiento": un análisis etnográfico sobre las dinámicas de consolidación en la situación de calle». Cuadernos de Trabajo Social, 27(2): 375-383.

Sumario: Introducción. 1. Contextualizando al estudio. 2. Los significados de hogar en quienes residen en Plaza Ópera. 3. Los procesos de apropiación y resignificación del espacio público. 4. Procesos de «atrincheramiento»: cuando el límite entre calle y hogar se torna borroso.

5. Reflexiones finales.

6. Referencias bibliográficas.

\section{Introducción}

El presente artículo es resultado de un trabajo etnográfico realizado, en el marco de mi tesis doctoral, entre el 2005 y el 2008, con personas que viven en las calles de Madrid; más específicamente, la mayor parte de las reflexiones to- man como epicentro a un grupo de personas sin hogar que reside en una plaza céntrica de la capital española, conocida como Plaza Ópera o Isabel II. El trabajo gira en torno a los significados de hogar subyacentes en las prácticas y discursos de estas personas sin hogar, pues los mis- 
mos nos permitirán abordar el objetivo específico del artículo, el cual consiste en analizar los «procesos de atrincheramiento» que refuerzan la situación de calle de estas personas. Entendiendo el atrincheramiento como un proceso de habituación al contexto de sinhogarismo, el artículo tiene por propósito analizar cómo las dificultades por superar la situación de calle se asocian con la socialización cotidiana en la vía pública ${ }^{1}$.

La estadía prolongada en la situación de calle marca profundamente a los sujetos, motivo por el cual algunas personas sin hogar llegan a sostener que la vía pública, el sitio en concreto donde residen, es su hogar. Otros, la gran mayoría, afirman sin vacilar que la calle no puede ser equiparada con su hogar. Sin embargo, buscando superar las limitaciones inherentes a residir en un territorio de exclusión como es el ámbito público, unos y otros se ven forzados a personalizar diariamente los sectores del espacio público donde residen. Significativamente, dichas prácticas y los discursos se ligan con el intento de asemejar a los espacios públicos temporalmente apropiados con dos ámbitos fundamentales en la vida de toda persona: el hogar y el trabajo. Debido a las características propias del espacio público, tales prácticas discursivas se encuentran condenadas al fracaso; no obstante, su examen clarifica cómo, tras años de socialización en la vía pública, él limite que separa los significados de calle y hogar comienza a difuminarse, mientas que la situación de sinhogarismo tiende a consolidarse.

\section{Contextualizando al estudio}

En el 2008, año en que concluyó la investigación doctoral, el dato más certero sobre la cantidad de personas sin hogar en España era el suministrado por el Instituto Nacional de Estadística (INE). Limitando su radio de acción a los dispositivos de atención a personas sin hogar, el INE (2005) llegó a una cifra de 21.900 personas en situación de calle. Posteriormente, hubo avances notables en lo que respecta a la generación de estadísticas sobre el fenómeno.
Así, el 12 de diciembre de 2006, el Foro Técnico de Personas sin Hogar (2006) implementó el primer censo madrileño dedicado a quienes pernoctan en la vía pública; entonces se contabilizaron 621 personas en las calles de la ciudad, mientras que unas 1.600 pasaron la noche en los diversos recursos sociales. Por otra parte, el último censo del INE (2012) revela que en este año 22.938 fueron atendidas en centros asistenciales. Asimismo, Sánchez Morales (2012) sostiene que la crisis socioeconómica española ha repercutido en lo que respecta al sinhogarismo. En Barcelona, el censo realizado en noviembre de 2011 arrojó la cifra de 2.791 personas sin hogar, lo cual supuso un incremento de la población de un 32 por ciento respecto del primer censo que fuera llevado a cabo en marzo del 2008. En el caso de Madrid, el 14 de febrero de 2011 se contabilizaron 1.900 personas sin hogar, cifra que representa un aumento del 4 por ciento en un año (Ibídem).

En lo que a la literatura académica sobre el sinhogarismo se refiere, en España es posible distinguir entre las perspectivas sociológicas (Cabrera, 1998; Tejero y Torrabadella, 2005) y otras de corte psicológico más vinculadas con los problemas de salud metal (Muñoz, Vázquez y Vázquez, 2003). Algunos trabajos se interesaron por aspectos concretos, como la vida de los inmigrantes en situación de calle (Sánchez Morales y Tezanos, 2004; Cabrera y Malgesini, 2002), las particularidades de las metodologías de recuento de personas sin hogar (Cabrera, 2007), los conflictos vinculados al uso del espacio público (Bachiller, 2009) cómo inciden las variables de género en el fenómeno (Escudero Carretero, 2003), o el funcionamiento de los servicios sociales dedicados a estas poblaciones (Vázquez Cabrera, 2003; Cabrera y Rubio, 2003).

Pretendiendo caracterizar al grupo que reside en Ópera, se torna preciso comparar al mismo con la población de personas sin hogar de España. En tal sentido, se trata de varones de nacionalidad española que superan la media nacional, tanto en lo que refiere a su edad como en lo que respecta al tiempo de estadía en situación

1 «Sinhogarismo» supone una traducción literal del termino homelessness, frecuentemente utilizado en inglés. Algo similar ocurre con la noción de «atrincheramiento», una traducción del término entrechment, el cual permite analizar cómo gradualmente la persona sim hogar incorpora una serie de hábitos propios de la experiencia de calle (Grigsby, Bauman, Gregorich y Roberts-Gray, 1990). 
de calle ${ }^{2}$. En segunda instancia, el grupo se singulariza por unas altas tasas de ingesta alcohólica y un marcado rechazo a relacionarse con los recursos sociales. Asimismo, los límites del grupo no son estables, por lo cual la cuantificación presenta un alto grado de arbitrariedad. Cuatro personas residieron de forma fija en Ópera a lo largo de los años que duró el trabajo de campo. Pero la mayoría responde a un patrón de sinhogarismo cíclico o episódico y acuden a la plaza en ciertas épocas del año o en función de las coyunturas. Reconociendo dichas fluctuaciones, es posible afirmar que en los cuatro años que duró la etnografía el grupo se conformó por un mínimo de cuatro personas durante el invierno, mientras que en el verano ascendían a unas veinte personas.

\section{Los significados de hogar en quienes resi- den en Plaza Ópera}

¿Cómo define al hogar alguien que reside en la vía pública? Responder a tal interrogante nos proporcionará pistas sobre los procesos de «atrincheramiento» que refuerzan la situación de calle de muchas personas. En primer lugar, debemos tener presente que el concepto de hogar no es universal. Existen múltiples sentidos, muchos de ellos contradictorios entre sí, pugnando en la conformación de una definición de hogar. Asimismo, dicha noción varía en función de factores como la biografía residencial, el género, la clase social, el tiempo de estadía en la situación de calle, el nivel de conservación de los lazos familiares o las pautas de movilidad (Tomas y Dittmar, 1995).

A pesar de la diversidad, los relatos de los miembros de Ópera coinciden en concebir al hogar como un espacio físico asociado con el cobijo y el calor. La calle es un entorno tan duro que predomina la nostalgia de sensaciones corporales placenteras; es decir, el hogar pasa a ser sinónimo de un techo, un bastión contra los caprichos climáticos o donde disfrutar de una ducha caliente. Se trata de lo más elemental: tratándose de personas que se sienten viejas y cansadas, el hogar también es asociado con un sitio donde sentirse seguros frente a posibles golpi- zas o robos, un entorno controlado en oposición al mundo externo; las permanentes amenazas propias de residir en el espacio público se traducen en un estrés que acompaña al individuo en situación de calle (Cabrera, 1998). A su vez, el hogar es el ámbito donde se realizan una serie de prácticas que en nuestra sociedad juzgamos claves para nuestro bienestar. Al preguntar qué significa un hogar luego de la experiencia de calle, muchas personas mencionaron cuestiones tan sencillas pero tan importantes como cocinar o la sensación del contacto con unas sábanas limpias.

Yo quisiera estar en un pisito, en una habitación, algo. Y tener un recogimiento. Ahora, por poner un ejemplo, que me han pagado una pensión, nada pues los días que más tarde llegaba a la pensión ha sido a las nueve de la noche. Y estaba como Dios. ¡Fenomenal! Me encontraba a gusto. En cambio aquí tienes que esperar a que se vaya la gente, a que encuentres cartones (...) por lo menos tengo sitio donde descansar, donde poder ver un rato la tele. Si llueve que llueva, y si quiere hacer calor que haga (Entrevista al Jirafa, 15 de marzo de 2005).

La segunda dimensión más destacada identifica al hogar como el espacio donde se despliega una serie de relaciones sociales fundamentales. Se trata del ámbito familiar: es entonces cuando la noción de hogar se asocia con el sentido de pertenencia. El hogar se transforma en un refugio que nos preserva frente a la hostili$\mathrm{dad}$, anonimato, racionalidad y competencia que caracterizan al mundo exterior (Tomas y Dittmar, 1995). En nuestra sociedad, el desarrollo más profundo de las afectividades ha sido reservado al hogar. La exclusión de las personas sin hogar responde a verse forzadas a residir en el espacio público, el cual es representado como la antítesis de un entorno de privacidad donde expresar las propias emociones. Cuando los informantes recuerdan con nostalgia la sensación de un hogar, pueden estar refiriéndose a jugar con un hijo o a un almuerzo familiar durante el fin de semana. En Ópera, llama la atención la cantidad de horas que las personas sin hogar pasan

2 El promedio de edad de las personas sin hogar en España es de 37 años (INE, 2005), mientras que en Ópera dicha media asciende a los 54 años. Asimismo, las personas sin hogar que residen en Madrid llevan un promedio de 3,56 años de estadía en la vía pública (Foro Técnico de personas sin hogar, 2006); al cierre de la tesis, en Ópera le tiempo de calle era de 82,54 meses —es decir, seis años y medio. 
juntos, lo cual conduce a desmitificar las imágenes de aislamiento radical. Sin embargo, dicha compañía no siempre logra superar un sentimiento generalizado de soledad, existe un vacío que sus «colegas» nunca logran llenar. A veces, dicha sensación de angustia remite a un presente que contrasta con lo perdido, nos recuerda lo lejos que nos encontramos de ese espacio de afectividad vital al cual llamamos «hogar».

La vida de la calle es dura porque te abandonas (...) y encima te sientes solo. Porque ahí, aunque nos veas hablando, y amigos y esto (...) no es lo mismo. ¿Me entiendes? Tener un cariño de tu mujer, de tus hijos, luchar por un hogar, como yo siempre he luchado por mis hijos, poderlos sacar adelante, claro, ahora ya no tienes ese ímpetu. Ahora muchas veces dices «bueno mira, que le den por culo y ya está, me quedo ahí» (Entrevista a Lionel, 15 de marzo de 2008).

Por consiguiente, a la hora de ser interpelados sobre si consideran a la calle como su hogar, quienes residen en Ópera suelen contestar negativamente: el hogar está en otro sitio y en otro tiempo, es el recuerdo de lo perdido o la añoranza de lo que nunca se tuvo, sintetiza la amarga sensación de ausencia y vació que predomina en estas personas. Por lo general, y más allá de las biografías residenciales, el término «hogar» despierta imágenes tan positivas que no pueden ser equiparadas con la calle.

No obstante, como consecuencia de residir en un ámbito hostil como es la calle, las personas se ven forzadas a apropiarse y modificar temporalmente el espacio público para garantizar su subsistencia. Debido a las características de la vía pública, tales esfuerzos por personalizar un sitio concreto de la ciudad nunca llegan a buen puerto. Sin embargo, dichas prácticas se repiten a lo largo del tiempo en un mismo espacio urbano, generando una socialización rutinaria e iniciando el proceso de atrincheramiento.

\section{Los procesos de apropiación y resignifica- ción del espacio público}

Considerando al sinhogarismo como la imposibilidad de residir en un ámbito privado, la apropiación y resignificación es un proceso inevitable que guarda relación con el uso de los territorios y los objetos, remite a la mutación de un espacio abstracto a un lugar practicado. Una vez que los elementos han sido alterados por el ser humano en función de sus necesidades y deseos, entonces adquieren un nuevo estatus; la esencia de la apropiación pasa por el proceso de distinción e identificación, supone personalizar los territorios, más allá de si hay una modificación del entorno (Lawrence y Low, 2003).

Los procesos de apropiación responden a que el espacio público es concebido por las personas sin hogar como un recurso básico para la subsistencia y socialización cotidiana. Más aún, la apropiación que realizan las PSH de las calles madrileñas se liga con el esfuerzo por reproducir dos ámbitos fundamentales en la existencia de todo ser humano: el trabajo y el hogar.

Quienes se ganan la vida ejerciendo la mendicidad en la vía pública suelen adoptar como propio un sitio concreto de la vía pública. En tales casos, es común que la persona sin hogar defina su actividad en términos similares a los de un trabajo (Rowe y Wolch, 1990). Esto es así no sólo por el beneficio económico que obtiene, sino también por emular el tipo de relaciones sociales que se generan en dichos ámbitos. Para poder ser identificado y sostener la relación con un benefactor, es necesario repetir una rutina en un mismo espacio urbano - por ejemplo, la puerta de una iglesia donde pedir limosnaGradualmente, las actividades realizadas en un espacio fijo reemplazan las redes que se conforman en otros ámbitos - familiar, laboral, etc.; a partir de entonces, muchas de los contactos cotidianos ocurren bajo tal contexto. A su vez, al fijar las interacciones con los vecinos del barrio en un tiempo y un espacio concreto, la persona sin hogar experimenta cierta sensación de «normalidad»; la repetición de las prácticas refuerza una percepción de continuidad espaciotemporal de los recorridos cotidianos (Ibídem).

Durante las noches de invierno las cajas de cartones son un elemento básico en la apropiación temporal del espacio público. Los cartones se convierten en una barrera que divide al territorio en función de la oposición dentro-fuera, estableciendo y remarcando actividades diferenciales en una y otra zona. Para quienes viven en la vía pública, el muro de cartones es la marca que ofrece un mínimo de privacidad en un área delimitada. Asimismo, las cajas de cartones adquieren múltiples usos asociados con el esfuerzo por adaptar y hacer más ameno un sitio determinado del espacio público. La cara interna de la caja de cartón, aquella que no da a la calle 
sino al portal que ha sido apropiado, adopta la forma de un armario donde guardar las pertenencias; otra caja suele ser improvisada como mesa en torno a la cual se juntan a dialogar quienes allí duermen, etc. En más de una ocasión me ocurrió que, al visitar durante la noche a un conocido, este me ofrecía un trozo de cartón como asiento y aislante del frío que emana del cemento. La decoración de los sitios representa otro ejemplo de cómo el sujeto intenta grabar su identidad en el espacio y hacerlo más placentero para la vida cotidiana. En distintos puntos de la ciudad me encontré con calcomanías, banderas, cuadros, pósteres de grupos de música o de fútbol recubriendo determinadas paredes, etc.

Debido a las limitaciones inherentes al espacio público, la voluntad por modificar y asemejar en lo posible un sector del territorio con un hogar, se expresa con mayor fuerza en el plano discursivo. Quienes llevan un tiempo en la calle suelen apelar a metáforas, a la terminología asociada con el hogar para referirse a las actividades que realizan cotidianamente, a los espacios donde residen, o a las relaciones sociales que allí establecen. El hogar es un espacio de socialización tan fuerte en nuestras vidas, que actúa como un marco interpretativo a partir del cual imaginamos buena parte del mundo social que nos rodea (Tomas y Dittmar, 1995). En las narrativas de estos hombres predominan los relatos que aluden al grupo como una «familia» o un «matrimonio», lo cual constituye otro ejemplo del proceso de asimilación del propio espacio social con un hogar. Esto sucede incluso con quienes niegan identificar a la Plaza Isabel II como su hogar, o con quienes se muestran particularmente críticos frente a sus compañeros.

Siempre salen discusiones. Esto es como un matrimonio. ¿Comprendes? Que tanto tiempo estás en casa que al final pues discutes. Por una tontería. Un matrimonio, llegas y «joder que no me has planchado la camisa». Y terminas discutiendo con la mujer. O sea, eso es lo mismo que un matrimonio (Entrevista a Ramón, 22 de agosto de 2007).

Como consecuencia de las características del espacio público, la vocación por asimilar al sector de la vía pública apropiada con un hogar es una batalla perdida de antemano. No obstante, el interés por destacar dichas prácticas reside en que tales esfuerzos grafican cómo, con el paso de los años, el límite que separa calle y hogar comienza a tornarse difuso.

\section{Procesos de «atrincheramiento»: cuando el límite entre calle y hogar se torna borroso}

$\mathrm{Al}$ indagar el proceso de «atrincheramiento» es preciso analizar la situación de una minoría de personas sin hogar que proclama que la calle es su hogar. Por lo general, se trata de personas con años de sinhogarismo a cuestas y con una biografía residencial marcada por una fuerte desestructuración. El proceso de «atrincheramiento» remite a cómo gradualmente el sujeto se va habituando al contexto de calle, cómo comienza a incorporar ciertos códigos característicos de quienes residen en la vía pública (Grigsby et al., 1990). Dicha dinámica supone el reemplazo de los lazos primarios por vínculos sociales con otras personas sin hogar —o con quienes se desempeñan en el circuito asistencial- Cuanto más se acostumbra la persona a la vida sin hogar, más se diluyen las posibilidades de escapar de tal entorno.

Como se sostuvo anteriormente, las dimensiones más básicas del hogar se ligan con el espacio físico y el relacional. El punto es que muchos de estos sujetos sostienen poseer un lugar $\mathrm{y}$ un grupo de referencia que otorgan un sentido de pertenencia, por lo cual rechazan las etiquetas que los califican como «sin hogar». Al respecto, resulta pertinente transcribir fragmentos de una discusión entre un informante clave y el líder de una ONG que centra su acción en las personas sin hogar.

Luciano dice que, al hablar en términos de persona sin hogar, el acento recae en el hogar en tanto espacio afectivo-relacional. Sostiene que él posee un lugar físico al cual siente como su hogar: el intercambiador de autobuses Avenida de América. Alega que quienes allí trabajan son, a esta altura, su familia, por lo cual le molesta que lo califiquen como «sin hogar» (...) El coordinador de la ONG disiente, opina que sus redes son muy inestables, que un hogar implica vínculos consolidados. Entonces Luciano le responde que sus actuales relaciones no son menos sólidas que las que tuvo con sus parientes (Cuaderno de Campo, 12 de enero de 2007).

Los procesos de atrincheramiento también operan en quienes, pese a llevar años residiendo 
en la calle, rechazan la posibilidad de definir a la misma como un hogar. Williams (1988) plantea que el hogar puede ser definido como una «estructura de sentimiento», como un ámbito vital para la socialización pues la vivencia rutinaria en dicho espacio condiciona las orientaciones subjetivas. Para las personas sin hogar no sólo el hogar, sino también la calle puede ser definida en tales términos. La socialización prolongada en la vía pública transforma las percepciones, altera los significados de calle y de hogar. Más aún, hogar y calle son conceptos que se retroalimentan, los cambios que afectan a una de tales nociones arrastran a la otra.

Nuestra casa representa un punto fijo en un universo móvil, inestable (Tomas y Dittmar, 1995). Si el propio hogar aporta identidad, también es como consecuencia de mostrarse como un bastión frente al cambio. Ahora bien, compartir un mismo escenario es un elemento clave en las redes de las personas sin hogar; dichos entornos y redes terminan reemplazando la función del hogar en tanto sostén de una continuidad espacio-temporal donde se desarrolla la propia identidad y autoestima (Rowe y Wolch, 1990). A pesar de no tener una estructura física a la cual llamar hogar, las personas sin hogar pueden haber desarrollado un sentimiento de pertenencia a través de su afiliación con sus «colegas» en un sitio concreto (Grigsby et. al., 1990). Ópera, para el grupo de personas sin hogar que allí reside, supone uno de los pocos puntos estables en sus vidas; es el ámbito al cual retornar todas las noches, el espacio donde transcurre la mayor parte de la cotidianidad.

Les conté que las vacaciones me hicieron bien, pues extrañaba a mis familiares y amigos. Entonces, el Jirafa comentó que le ocurrió lo mismo cuando estuvo trabajando en las cosechas en Portugal. «Y eso que estaba bien, comía de puta madre, me daban unos churrascos que no veas. Pero me faltaba algo. Este es mi ambiente, extrañaba a estos cuatro bribones (Cuaderno de campo, 19 de septiembre de 2005).

Es digno de destacar la dificultad por establecer una distinción clara entre «calle» $\mathrm{y}$ «hogar» en muchos de quienes lograron abandonar temporalmente la vía pública como sitio donde pernoctar. La misma guarda relación con un proceso de socialización marcado por un patrón de «sinhogarismo cíclico». La modalidad más típica de sinhogarismo radica en una constante inestabilidad residencial antes que en una situación permanente de calle; la persona entra y sale una y otra vez de la vía pública, alternando temporadas donde duerme a la intemperie con otras donde dispone de un techo bajo el cual refugiarse.

Se ríen de Lionel, quien se ha quedado dormido en un banco de la plaza. Bruno comenta: «iTeniendo una pensión en Puerta del Sol y durmiendo aquí! ¡Hay que ser gilipollas!». Luis agrega: «entre el que se quiere marchar, y el que quiere volver, al final no sacas a ninguno de aquí». Viendo a Lionel y pensando en la posibilidad de una habitación, Alfredo comenta: «el día que agarre una cama (...) ¡sabes como la dejo! ¡Bah! Quizás ese día termino tirando los cartones en el piso y durmiendo en el suelo. ¡No veas!» (risas) (...) Bruno añade, siempre tomando a Lionel como centro de sus críticas: "ilo que no se puede es gastarse 300 euros en un día! Si consigue dinero y vuelve siempre a la calle» (Cuaderno de campo, 1 de marzo de 2006).

La experiencia de calle deja marcas imborrables en quienes han pasado una temporada bajo sus dominios. De alguna que otra forma, muchos de los que han escapado del sinhogarismo vuelven a Ópera. Es el caso de Federico, que consiguió un empleo como fontanero y, al finalizar la jornada laboral, suele acercarse a la plaza a beber y compartir unas horas con los antiguos compañeros. Las relaciones sociales siguen circunscriptas a Ópera, por más que la persona ya no resida allí. El miedo a verse inmerso en un nuevo proceso de calle explica las visitas a Plaza Ópera y los esfuerzos por preservar las relaciones con las personas sin hogar: en caso de una recaída, Federico sabe que allí será bienvenido. El sinhogarismo cíclico o episódico empapa de inseguridad al sujeto, quien no logra experimentar a ningún sitio como un auténtico hogar, sino que los vive como refugios temporales. La sensación de soledad se erige en otro factor digno de consideración. En definitiva, las modalidades de sinhogarismo también responden a tener o no tener un espacio/grupo como referencia vital.

Mariana me cometa que está contenta, viviendo en un piso protegido con una compañera marroquí —una «excelente persona»-. Pero su 
discurso subrepticiamente cambia de tono. «Estoy bien, pero el edificio es diferente. Esta chica no está en todo el día, se pasa el día trabajando». Continúa informándome que ni bien se despertó vino a buscar a alguno de los amigos que conoció durmiendo en la calle. «Más ahora en las fiestas, en el edificio me siento sola. ¡Es que nunca estás completa, siempre te falta algo!» (Cuaderno de campo, 5 de diciembre de 2007).

En ocasiones, la vuelta a las calles no se da simplemente bajo la forma de una visita, sino como el retorno a la situación de exclusión residencial más extrema. Luego de una temporada, salir de la calle se torna muy difícil, pero mucho más duro aún suele ser mantener un domicilio sin «reincidir» en el sinhogarismo (Muñoz et al., 2003). En consecuencia, cuando una persona consigue una habitación o un piso, muchas veces reproduce pautas típicas de la calle. Asimismo, Snow y Anderson (1993) han observado que muchas de estas personas no logran compartir un sentido de pertenencia con quienes disfrutan de un domicilio, añoran poder conversar sobre su pasado con gente que ha vivido experiencias similares. Los hábitos adquiridos en la calle generan discrepancias cognitivas con la vida domiciliada; es decir, en ocasiones los códigos de calle entran en colisión con lo que establece el sentido común o las reglas de convivencia hegemónicas.

He conocido a más de una persona que mencionaba estar demasiado acostumbrada a la calle, que ese es el medio que mejor conocen y donde saben desenvolverse, y que no logran adaptarse a lo que entienden como «responsabilidades del hogar» — situaciones que son descritas como de «agobio», tales como tener que pagar los impuestos-. Quienes llevan muchos años en la calle, llegan inclusive a plantear que les resulta imposible acostumbrarse nuevamente a dormir en una cama, que no soportan la sensación de claustrofobia ni el silencio de una habitación con sonidos tan diferentes a los que están habituados a escuchar en las calles madrileñas. Así, cuando el sujeto pasó muchos años residiendo en la vía pública y la situación de calle se ha consolidado, el alojamiento estable puede ser visto como sinónimo de aislamiento y distancia respecto del ambiente en el cual han pasado los últimos años, comienza a desdibujarse como posibilidad real en su gama de opciones.

\section{Reflexiones finales}

El objetivo del artículo consistió en indagar los significados de hogar presentes en los discursos y prácticas de un grupo de personas sin hogar, en tanto una forma de desentrañar los procesos de atrincheramiento o afianzamiento en la situación de calle.

De tal modo, se examinaron los esfuerzos que las personas sin hogar realizan por apropiase y personalizar temporalmente determinados sitios del espacio público, intentando asemejarlos con un hogar. Si bien se reconoció que dichos esfuerzos están condenados al fracaso, también se subrayó que los mismos son claves en el análisis de la socialización cotidiana de las personas sin hogar en el espacio público. Los procesos de consolidación en la situación de calle guardan relación con la experiencia rutinaria: a medida que transcurren los años y el sinhogarismo se prolonga, las fronteras que delimitan las nociones de calle y hogar tienden a volverse borrosas.

La estadía prolongada en la situación de calle deja huellas irreparables, motivo por el cual muchas personas terminan atrincherándose en el sinhogarismo. Así, algunos individuos llegan a sostener que la vía pública, el sitio en concreto donde residen, es su hogar. Otras, y este es el caso más común, niegan rotundamente dicha posibilidad. El hogar, en tanto espacio idealizado aunque no necesariamente vivido, suele ser asociado con imágenes tan positivas que no puede ser equiparable al lugar donde actualmente residen. No obstante, al afrontar día a día la experiencia de calle, sus relatos contradicen esta afirmación: luego de años de sinhogarismo, el sujeto adopta una postura ambivalente respecto de las nociones de calle y hogar.

La vía pública es su cotidianidad, y tal hecho transforma las percepciones. Cada intento de «reinserción» que culmina en fracaso, en una nueva temporada en la vía pública, refuerza la sensación de que ese es su destino. Cuando consiguen un techo bajo el cual refugiarse, vuelven a la plaza a visitar a «los colegas», pues allí se localizan sus lazos sociales más importantes. Es en los alrededores de la Plaza Isabel II donde continúan ganándose la vida a partir de las diversas maneras en que se expresa la economía informal. Es en Ópera donde saben que encontrarán compañía dispuesta a compartir un cartón de vino. Las experiencias previas los han adver- 
tido de los golpes de fortuna, y cuando encuentran una vivienda se muestran inseguros, sospechan que en poco tiempo todo se derrumbará y acabarán nuevamente en la plaza. En definitiva, cuando consiguen una vivienda no logran transformarla en un hogar.

De tal modo, los años de socialización en la vía pública conllevan que sea difícil escapar de la exclusión extrema, pero más duro aún resulta no reincidir en la situación de calle. Luego de un período prolongado de calle el círculo de la exclusión tiende a cerrarse, la persona se acostumbra al contexto residencial y deja de preocuparse por encontrar una salida, o busca alternativas residenciales para finalmente sumergirse en el sinhogarismo cíclico. Lo recurrente en la vida de esta gente es la inestabilidad residencial por lo cual, luego de una experiencia prolongada de sinhogarismo, no son capaces de establecer una distinción tajante entre la calle y el hogar. Es entonces cuando las posibilidades de «reinserción» se reducen a un mínimo.

Me gustaría volver a tener un techo, todo lo que tenía antes, pero no sé, porque me metieron en un piso (protegido) y acabe agobiado (...) ya coges la costumbre. Ya lo ves como eso, como una parte de tu vida. El arbusto adonde estoy. Estoy muy acostumbrado a ese lado y es lo que hay, como si fuera mi hogar (...) A mí me gustaría en el futuro poder salir adelante bien, que me toque una lotería. Poder mandar a la mierda todo esto y empezar a vivir bien. Lo primero que haría sería comprarme una casa, ponerla pa' mi. Eso sería lo primero que haría. Luego ya me agobio, la alquilo y sigo aquí, pero por lo menos tengo un sitio para meterme cuando sea ya mayor (risas) (Entrevista a Diego, 21 de diciembre de 2007).

A nivel de posibles futuras líneas de investigación, compatibles con los programas de reinserción social, se sostiene la necesidad de focalizarse en la evolución de la sociabilidad de las personas sin hogar en función del tiempo de residencia en la vía pública. El sujeto reconstruye sus tácticas de subsistencia y relaciones sociales en la calle; con el paso del tiempo, es en dicho medio donde se siente más seguro y sabe desenvolverse. La estadía prolongada en el sinhogarismo trastoca las orientaciones cognitivas de los sujetos; a partir de entonces, los sentimientos de desconfianza o la pérdida de autoestima se apoderan del individuo y difícilmente logren ser completamente desterradas. Luego de años en la vía pública, iniciar un proceso de «reinserción» se torna especialmente difícil y muy costoso en términos económicos. Los programas de lucha contra el sinhogarismo deberían ser capaces de detectar y actuar rápidamente cuando una persona comienza a pernoctar en la vía pública; para ello, es necesario reforzar el trabajo en el terreno. De modo similar, sería importante diversificar aún más las modalidades de intervención de acuerdo al tiempo de estadía en la vía pública.

\section{Referencias bibliográficas}

Bachiller, S. (octubre-diciembre, 2009). Significados del espacio público y la exclusión de las personas sin hogar como un proceso de movilidad forzada. Revista Española de Investigaciones sociológicas 128 .

Cabrera, P. J. (2007). Las metodologías S-Night para la detección de personas sin hogar: límites y posibilidades. Ponencia presentada en el IX Congreso Español de Sociología, Barcelona, España.

Cabrera, P. y Rubio, M. J. (2003). Personas sin Techo en Madrid. Diagnóstico y Propuestas de actuación. Madrid: Universidad Pontificia de Comillas.

Cabrera, P. J. y Malgesini, G. (2002). Inmigrantes y sinhogarismo en España. Informe Nacional 2001-2002. Bruselas: FEANTSA.

Cabrera, P. J. (1998). Huéspedes del aire. Sociología de las personas sin hogar en Madrid. Madrid: Universidad Pontificia Comillas.

Escudero Carretero, M. J. (2003). Mujeres sin hogar en Granada. Un estudio etnográfico. Granada: Instituto Andaluz de la Mujer.

Foro Técnico de Personas sin Hogar. (2006). Operación de recuento nocturno de personas viviendo sin techo en las calles de Madrid. Madrid: Ayuntamiento de Madrid.

Grigsby, C., Bauman, D.; Gregorich, S. E. y Roberts-Gray, C. (1990). Disaffiliation to entrenchment: a model for understanding homelessness. Journal of Social Issues, 46 (4).

Instituto Nacional de Estadística. (2012). Encuesta a las Personas sin hogar. Recuperado de: http://www.ine.es/prensa/np761.pdf. 
Instituto Nacional de Estadística. (2005). Encuesta Sobre Personas sin hogar. Recuperado de: http://www.ine.es/prensa/np398.pdf.

Lawrence, D. L. y Low, S. (2003). Locating culture. En D. Lawrence y S. Low (eds.). The anthropology of space and place: locating culture. Malden: Blackwell Publishers Ltd.

Muñoz, M., Vázquez, C. y Vázquez, J. J. (2003). Los límites de la Exclusión. Estudio sobre los factores económicos, psicosociales y de salud que afectan a las personas sin hogar en Madrid. Madrid: Témpora y Caja Madrid.

Rowe, S. y Wolch, J. (1990). Social Networks in Time and Space: Homeless Women in Skid Row, Los Angeles. Annals of the Association of American Geographers, 80 (2).

Sánchez Morales, M. R. (2012). Las personas «sin hogar» en tiempos de crisis. Recuperado de: http://www.noticiaspsh.org/spip.php?article4816.

Sánchez Morales, M. R. y Tezanos Vázquez, S. (diciembre, 2004). Los inmigrantes sin hogar en España: un caso extremo de exclusión social. Revista del Ministerio de Trabajo y Asuntos Sociales, 55.

Snow, D. y Anderson, L. (1993). Down on their luck. A study of homeless street people. Los Angeles: University of California Press.

Tejero, E. y Torrabadella, L. (2005). Vides al descobert. Els mons viscuts del fenomen sense sostre. Barcelona: Mediterrània.

Tomas, A. y Dittmar, H. (1995). The experience of homeless woman: an exploration of housing histories and the meaning of home. Housing Studies 10 (4).

Vázquez Cabrera, J. J. (2003). Los recursos básicos de la atención a las personas sin hogar en Madrid desde la perspectiva de los usuarios. Madrid: Consejo Económico y Social de la Comunidad de Madrid.

Williams, B. (1988). Upscalling Downtown: Stalled Gentrification in Washington D.C. Ithaca: Cornell University Press. 